\title{
Research on the Influence of Entrepreneurs' Creative Thinking and Optimism Degree on Innovation Opportunity Identification
}

\author{
Dongping $\mathrm{Yu}$ \\ International Business School \\ Yunnan University of Finance and Economics \\ Kunming, China \\ 247096657@qq.com \\ Jingfei Wang* \\ International Business School \\ Yunnan University of Finance and Economics \\ Kunming, China \\ 864639017@qq.com
}

\author{
Zhengyang Meng \\ International Business School \\ Yunnan University of Finance and Economics \\ Kunming, China \\ 386818100@qq.com \\ Sai Zhao \\ International Business School \\ Yunnan University of Finance and Economics \\ Kunming, China \\ 739457672@qq.com
}

\begin{abstract}
Innovative entrepreneurial activities originate from the identification of entrepreneurs' opportunities for innovation. Using the questionnaire survey method, the hypothesis of complex relationship between entrepreneurial creative thinking, optimism degree and innovation opportunity identification was proposed and tested. The results show that there is a significant inverted $U$-shaped relationship between entrepreneurial creative thinking, optimism degree and innovation opportunity identification; Optimism degree positively regulates the promoting effect of creative thinking on innovation opportunity identification.
\end{abstract}

Keywords: creative thinking, optimism degree, innovation opportunity identification, entrepreneur

\section{INTRODUCTION}

Innovation is the driving force for the sustainable development of enterprises. Looking at contemporary enterprises, only by continuous innovation can enterprises stand in the forest of the strong in the competition. With the effective promotion of China's "mass entrepreneurship and innovation" policy, China's innovation and entrepreneurship activities ushered in a golden period. Innovative entrepreneurial activities stem from the identification of innovation opportunities by entrepreneurs. Therefore, entrepreneurs must effectively solve the problem of identifying innovation opportunities in innovation and entrepreneurship activities [1]. The so-called innovation opportunity identification refers to the decision of the individual to pursue or abandon the development of a specific opportunity that is conducive to innovation at a certain point in time [2]. The ability to identify opportunities for innovation determines the success or failure of entrepreneurial behavior [3]. Through combing existing literatures, this paper found that since the 1970s, many scholars have discussed the relationship between innovative thinking and entrepreneurial opportunity identification from different perspectives and methods, but few studies on the internal mechanism of creative thinking and entrepreneurial opportunity identification. Zhang xiue pointed out that creative thinking is an important factor in the innovation opportunity identification. Ardichvili emphasizes that entrepreneurial alertness is an important factor in the entrepreneurial opportunity identification, and that entrepreneurial personal traits and existing knowledge are the previous factors of entrepreneurial alertness, but they do not empirically analyze the proposed theory [4]. It is difficult to comprehensively explore the deep academic value of innovation opportunity identification, and it is also not conducive to the specific implementation of entrepreneurship education practice.

In order to effectively solve the above problems, this paper is based on previous studies, using creative thinking and optimism degree as explanatory variables, innovation opportunity identification as explanatory variables, and optimism degree as moderating variables, and the complex relationship hypothesis between them is proposed. The literature review method is used, and the hypothesis is verified based on the questionnaire data, in order to provide theoretical support and practical help for entrepreneurs to carry out innovation and entrepreneurial activities.

\section{LITERATURE REVIEW AND RESEARCH HYPOTHESIS}

\section{A. Entrepreneurial Creative Thinking and Innovation Opportunity Identification}

The so-called creative thinking refers to the individual's thinking form that produces novel, unique, applicable ideas or products, which plays a key role in scientific discovery, invention creation and other activities [5]. In entrepreneurial activities, potential entrepreneurs with creative thinking can more easily discover obvious or inconspicuous connections

*Corresponding author 
between things, and reshape or change existing resources to identify good entrepreneurial opportunities. With regard to the study of creative thinking and innovative opportunity identification, many domestic and foreign scholars have explained the relationship between creative thinking and innovative opportunity identification through theoretical deduction. Zhang xiue took 180 entrepreneurs from small and medium-sized enterprises in Jilin Province as samples and found that creative thinking has a positive impact on the innovative opportunity identification and the profitability and feasibility of opportunities [6]. Ko and Butle found that creative thinking has a positive impact on entrepreneurial opportunity identification, and creative thinking plays a mediating role between entrepreneurial alertness and entrepreneurial opportunity identification [7]. However, some scholars have pointed out that there is not a simple linear relationship between creative thinking and opportunity identification. For example, Yao empirically verified the moderating effect of the doctrine of the mean on the relationship between creative thinking and innovative behavior [8]. When the individual's doctrine of the mean is deep, his creative thinking has nothing to do with innovation. When the individual's mediocrity is weak, his creative thinking is significantly related to his innovative behavior .

Based on the above discussion, this paper proposes the following assumptions:

H1. There is an inverted U-type relationship between entrepreneurial creative thinking and innovation opportunity identification. That is, too low or too high creative thinking is not conducive to entrepreneurs to identify innovative opportunities, and entrepreneurs with moderate creative thinking have the best ability to identify innovative opportunities .

\section{B. Entrepreneurial Optimism and Innovation Opportunity Identification}

The optimism degree refers to the individual's belief in achieving difficult goals. Optimism is a common emotion of entrepreneurs, and it is of great significance to support entrepreneurs' actions. The different optimism degree of entrepreneurs leads to different entrepreneurial behaviors. Niu Fang and others pointed out that self-confidence and optimism can reduce entrepreneurs' perception of entrepreneurial risk and enhance their entrepreneurial willingness, thus facilitating innovation opportunity identification [9]. Goel and Thakor argue that overconfidence encourages entrepreneurs to take a broader range of exploration and risk-taking behaviors to create value for the company [10]. However, Malmendier and Tate found that overconfident entrepreneurs often have uneconomic mergers and sub-optimal investment behaviors that undermine corporate value [11]. Xie yaping and Wang guolin have shown that overly pessimistic or optimistic emotional perception is not conducive to the formation and development of innovation ability, while family members driven by moderately optimistic emotions can constantly generate internal motivation conducive to action, which is more conducive to the innovation opportunity identification [12].
Based on the above discussion, this paper proposes the following assumptions:

$\mathrm{H} 2$. There is an inverted u-shaped relationship between entrepreneurs' optimism degree and innovation opportunity identification, that is, entrepreneurs' too low self-esteem or too confident are not conducive to their identification of innovation opportunities, and moderately optimistic entrepreneurs have the most ideal innovation opportunity identification ability.

\section{The Moderating Effect of Entrepreneurs' Optimism Degree}

With the rise of entrepreneurial research, entrepreneurial cognition is considered to be an important key to uncover the mystery of the entrepreneurial process, and creative thinking is an information processing capability of the cognitive process, which can effectively improve the feasibility and profitability of recognized opportunities. The optimism as an important cognitive feature of entrepreneurs has also begun to attract the attention of researchers. Optimism can significantly affect an individual's behavior and state, and has a significant impact on entrepreneurs. Confidence and optimism enable entrepreneurs to have confidence in their abilities and maintain a positive attitude towards the future, to withstand setbacks and failures, and to experience less stress, anxiety and depression in adversity and difficulties. In the process of starting up a business, optimism can reduce the entrepreneur's perception of entrepreneurial risks, help improve his creative thinking, and then improve his willingness to start up a business [13]. Optimism has an important impact on the effectiveness and learning outcomes of entrepreneurs. Individuals driven by optimism are constantly motivated to take action and are more likely to treat and feel the stimuli around them with appreciation, thus broadening their cognitive scope and taking effective entrepreneurial actions to improve their entrepreneurial ability [14]. On the other hand, inspired by optimism, entrepreneurs are more likely to come up with creative ideas and put them into practice. Therefore, there is a certain interaction between optimism degree and creative thinking, which has an important impact on the entrepreneurs' innovation opportunity identification.

Based on the above discussion, this paper proposes the following assumptions:

H3. Entrepreneur's optimism degree positively regulates the positive effect between entrepreneur's creative thinking and innovation opportunity identification, that is, optimistic mood will strengthen the promotion effect of creative thinking on innovation opportunity identification.

Through the above analysis, this paper forms the research framework of the following figure:

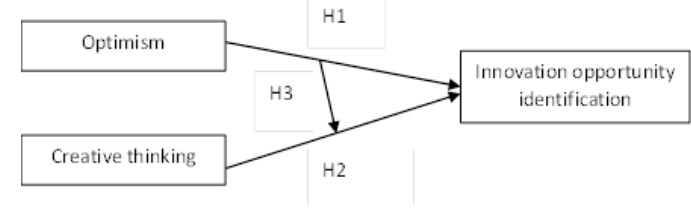

Fig. 1. Conceptual model 


\section{RESEARCH DESIGN}

\section{A. Variable Measurement s}

\section{1) Interpret variables}

Entrepreneurs' creative thinking (represented by Cre) scale mainly refers to the research results of Ardichvili, using the Likert 7-level scale (where 1 means completely disagree, 7 means complete agree), setting "the company executives often come up with new ways to achieve goals" (remarked as Cre1) and "company executives often come up with new ideas to improve performance" (remarked as Cre2), "the company executives can often find new technology, new process, new techniques or new products information" (remarked as Cre3), "the company executives often adopt new methods to improve the quality of work" (remarked as Cre4), "the company executives often have new breakthrough ideas" (remarked as Cre5), "the company executives are not afraid of any risk" (remarked as Cre6), "the company executives will pass new ideas to others" (remarked as Cre7), "the company executives often design a suitable plan and schedule to realize new ideas" (remarked as Cre8), "the company executives often offer creative solutions to problems" (remarked as Cre9), "the company executives often apply different solutions to problems " (remarked as Cre10) 10 measurement problem item [4].

Entrepreneurs' optimism degree (expressed by Opt) scale mainly refers to the research results of Ardichvili, using the Likert 7-level scale, setting "when encountering setbacks, the company executives will challenge themselves" (remarked as Opt1) ), "the company executives are full of good expectations for the future (remarked as Opt2)", "the company executives always take a proactive attitude towards things" (remarked as Opt3), "the company executives dare to accept difficulties" (remarked as Opt4), "When encountering setbacks, the company executives never give up" (remarked as Opt5), "the company executives are people who can think and look forward to success" (remarked as Opt6), " Company executives can face pressure and difficulties" (remarked as Opt7), "When faced with setbacks, the company executives can quickly find a solution" (remarked as Opt8), "when encountering setbacks, the company executives dare to challenge themselves" (remarked as Opt9), "the company executives are full of good expectations for the future" (remarked as Opt10) 10 measurement problem items [4]

\section{2) Interpreted variables}

The innovation opportunity identification (remarked as Idt) scale mainly refers to the measurement method of Ozgen, using the Likert 7 -scale scale (1 means completely disagree, 7 means complete agree), setting " the company executives can always find unmet needs in their work and life. " (remarked as Idt1), "the company executives can always find resources that are not fully utilized in their work and life. " (remarked as Idt2), "even if there is no experience in an industry, the company executives can find entrepreneurial opportunities". (remarked as Idt3), "In daily life, the company executives can always identify the entrepreneurial opportunities that exist around them" (remarked as Idt4), " In the past, there has been no correlation between the entrepreneurial opportunities identified by company executives." (remarked as Idt5) ,"In order to identify good entrepreneurial opportunities, the company executives often conduct in-depth research on an industry or market" (remarked as Idt6) 6 measurement problem items [15].

\section{3) Control variables}

Given the potential impact of entrepreneur gender, age, founder identity, company position, company nature, company size and other variables on the innovation opportunity identification, this article also considers gender (remarked as Gender, "0" = female, "1" = male ), age (remarked as Age, "1" $=30$ years old and below, "2" = 31 to 39 years old, " $3 "=40$ to 49 years old, "4" = 50 years old and above), founder status (remarked as Founder, "0" = no, "1" = yes), company position (remarked as Function, "1" = other, "2" = middle management, "3" = top management), company nature (remarked as Nature, $" 1 "$ = state-owned sole proprietorship, "2" = collective enterprise, "3" = share cooperative enterprise, "4" = joint venture, "5" = limited liability company, "6" = joint stock company, "7 "= private enterprise, "8" = foreign and Hong Kong, Macao and Taiwan investment enterprises, "9" = other), company size (remarked as Size, "1" = large, "2" = medium, "3" = small), etc. variable.

\section{B. Data Research}

The hypothesis test is carried out by means of questionnaires, mainly considering that the scientific and effective nature of the method in relational relationship testing has been widely recognized by the academic community, and its many advantages in data collection time, quality, cost, etc. meet the actual needs of this study. This paper uses the rolling method to issue questionnaires to business managers in MBA students in various universities in Yunnan Province. The survey lasted for half a year, and 300 questionnaires were distributed and 201 copies were recovered. The recovery rate was $67 \%$. After eliminating the invalid questionnaire, a total of 187 valid questionnaires were finally collected. The specific statistical characteristics are as follows (Table I).

TABLE I. SAMPLE STATISTICAL CHARACTERISTICS

\begin{tabular}{|c|c|c|c|}
\hline item & type & frequency & $\begin{array}{c}\text { frequency } \\
(\%)\end{array}$ \\
\hline \multirow[t]{4}{*}{ Gender } & $0=$ female & & \\
\hline & & 99 & 52.9 \\
\hline & $1=$ male & & \\
\hline & & 88 & 47.1 \\
\hline \multirow[t]{8}{*}{ Age } & $1=30$ years old and belowe & & \\
\hline & & 55 & 29.4 \\
\hline & $2=31-39$ years old & & \\
\hline & & 96 & 51.3 \\
\hline & $3=40-49$ years old & & \\
\hline & & 36 & 19.3 \\
\hline & $4=50$ years old and above & & \\
\hline & & 0 & 0 \\
\hline \multirow[t]{4}{*}{ Founder } & $0=$ no & & \\
\hline & & 161 & 86.1 \\
\hline & $1=$ yes & & \\
\hline & & 26 & 13.9 \\
\hline \multirow[t]{8}{*}{ Function } & $1=$ top managemen & & \\
\hline & & 49 & 26.2 \\
\hline & $2=$ middle management & & \\
\hline & & 69 & 36.9 \\
\hline & $3=$ basic management & & \\
\hline & & 42 & 22.5 \\
\hline & $4=$ general staff & & \\
\hline & & 27 & 14.4 \\
\hline
\end{tabular}




\begin{tabular}{|l|l|c|c|}
\hline Nature & $\begin{array}{l}1=\quad \text { state-owned sole } \\
\text { proprietorship }\end{array}$ & 3 & 1.6 \\
\cline { 2 - 4 } & 2= collective enterprise & 40 & 21.4 \\
\cline { 2 - 4 } & 3= share cooperative enterprise & 3 & 1.6 \\
\cline { 2 - 4 } & 4= joint venture & 6 & 3.2 \\
\cline { 2 - 4 } & 5= limited liability company & 5 & 2.7 \\
\cline { 2 - 4 } & 6= joint stock company & 24 & 12.8 \\
\cline { 2 - 4 } & 7= private enterprise & 44 & 23.5 \\
\cline { 2 - 4 } & $\begin{array}{l}\text { 8= foreign and Hong Kong, } \\
\text { Macao and Taiwan investment }\end{array}$ & 34 & 18.2 \\
\cline { 2 - 4 } & $9=$ other & 16 & 8.6 \\
\hline Size & 1= large & 65 & 45.5 \\
\cline { 2 - 4 } & $2=$ medium & 42 & 22.5 \\
\cline { 2 - 4 } & $3=$ small & & \\
\hline
\end{tabular}

\section{Reliability and Validity Check}

The internal consistency of the variables was tested using Cronbach's $\alpha$ coefficient. The results show that the Cronbach's $\alpha$ coefficient of creative thinking is 0.913 , the Cronbach's $\alpha$ coefficient of optimistic degree is 0.951 , and the Cronbach's $\alpha$ coefficient of innovation opportunity identification is 0.867 , which indicates that the questionnaire has good reliability.

For factor analysis, the relevant data was first tested using the KMO test and the Bartlett sphere test. The results show that the KMO value of entrepreneurial creative thinking and optimism degree is 0.930 , and the KMO value of innovation opportunity identification is 0.830 , which is greater than the usual 0.7 standard, indicating that the sample data is suitable for exploratory factor analysis. The significance probability of approximate chi-square statistical values of Bartlett sphere test is 0.000 , less than 0.001 of significance level, which indicates that there is a strong correlation between variables.

Based on the above detection results, factors of explanatory variables and explained variables were extracted by principal component analysis, and the factor analysis load matrix was obtained by means of variance maximization rotation, as shown in TABLE II. When principal component analysis was carried out with the eigenvalue greater than 1 as the factor extraction standard, 18 variables were extracted into 3 factors, each factor covers a number of variables whose load is greater than 0.5 , which indicates that there is a significant correlation between the variables included in the factor.

TABLE II. ROTATION COMPONENT MATRIX

\begin{tabular}{|c|c|c|c|c|}
\hline \multirow[t]{2}{*}{ Factor } & \multirow[t]{2}{*}{ Item } & \multicolumn{3}{|c|}{ Ingredients } \\
\hline & & 1 & 2 & 3 \\
\hline \multirow{5}{*}{ Creative thinking } & Cre1 & 0.359 & 0.756 & 0.019 \\
\hline & $\mathrm{Cre} 2$ & 0.241 & 0.802 & 0.246 \\
\hline & Cre3 & 0.200 & 0.810 & 0.243 \\
\hline & Cre4 & 0.203 & 0.851 & 0.201 \\
\hline & Cre5 & 0.259 & 0.754 & 0.325 \\
\hline \multirow{8}{*}{ Optimism degree } & Opt3 & 0.634 & 0.372 & 0.393 \\
\hline & Opt4 & 0.792 & 0.255 & 0.296 \\
\hline & Opt5 & 0.810 & 0.207 & 0.317 \\
\hline & Opt6 & 0.736 & 0.191 & 0.258 \\
\hline & Opt7 & 0.802 & 0.282 & 0.216 \\
\hline & Opt8 & 0.768 & 0.294 & 0.330 \\
\hline & Opt9 & 0.766 & 0.297 & 0.368 \\
\hline & Opt10 & 0.774 & 0.229 & 0.291 \\
\hline \multirow{5}{*}{$\begin{array}{c}\text { Innovation opportunity } \\
\text { identification }\end{array}$} & Idt1 & 0.401 & 0.286 & 0.536 \\
\hline & Idt2 & 0.390 & 0.338 & 0.672 \\
\hline & Idt3 & 0.339 & 0.128 & 0.777 \\
\hline & Idt 4 & 0.307 & 0.170 & 0.804 \\
\hline & Idt6 & 0.321 & 0.390 & 0.57 \\
\hline
\end{tabular}

To initially test the correlation between the variables, they were included in the Pearon correlation coefficient matrix, and the results are shown in TABLE III. It can be seen from TABLE III that there is a significant positive correlation between the entrepreneurial creative thinking, the natural items of optimism degree and the innovation opportunity identification, and there is a significant negative correlation between the squared items and the innovation opportunity identification, which preliminarily verifies the previous hypothesis.

TABLE III. CORRELATION BETWEEN VARIABLES

\begin{tabular}{|c|c|c|c|c|c|c|c|c|c|c|c|}
\hline & Gender & Age & Founder & Function & Nature & Size & Cre & Opt & Cre2 & Opt2 & Idt \\
\hline Gender & 1 & & & & & & & & & & \\
\hline Age & -0.001 & 1 & & & & & & & & & \\
\hline Founder & -0.131 & $0.238 * *$ & 1 & & & & & & & & \\
\hline Function & 0.084 & $-0.505^{* *}$ & $-0.487 * *$ & 1 & & & & & & & \\
\hline Nature & 0.105 & 0.064 & $0.159^{*}$ & $\begin{array}{l}-0.187 * \\
\end{array}$ & 1 & & & & & & \\
\hline Size & -0.009 & $0.160^{*}$ & $0.489^{* *}$ & $-0.305 * *$ & $0.329^{* *}$ & 1 & & & & & \\
\hline Cre & -0.048 & 0.049 & -0.055 & -0.065 & $0.220^{* *}$ & -0.018 & 1 & & & & \\
\hline Opt & $-0.203^{* *}$ & $0.153^{*}$ & 0.040 & -0.134 & -0.076 & -0.030 & 0.000 & 1 & & & \\
\hline $\mathrm{Cre}^{2}$ & 0.048 & 0.003 & 0.013 & 0.007 & -0.060 & -0.052 & 0.099 & $-0.200 * *$ & 1 & & \\
\hline$O \mathrm{pt}^{2}$ & 0.096 & 0.044 & -0.012 & -0.024 & 0.020 & -0.059 & -0.008 & $-0.225^{* *}$ & $0.646^{* *}$ & 1 & \\
\hline Idt & $-0.147 *$ & 0.011 & 0.065 & $-0.154^{*}$ & 0.051 & -0.006 & $0.232^{* *}$ & $0.631^{* *}$ & $-0.217 * *$ & $-0.246 * *$ & 1 \\
\hline
\end{tabular}




\section{RESULTS ANALYSIS}

This paper refers to the hypothesis test sequence of Cui bei and Wang yuxia and verifies the hypotheses one by one [16]. The first step is to control the regression analysis of the innovation opportunity identification to control the influence of individual factors. The second and third steps, after adding the control variables, add the natural and square terms of creative thinking and optimism degree to test the explanatory variables. Whether there is an inverted U-shaped relationship with the interpreted variable. The third step is to add control variables, creative thinking, optimism degree and the interaction variables of creative thinking to test whether the optimism degree plays a regulatory role between the interpret variables and the interpreted variables. Each variable was included in the model one by one, and the Enter regression method was used to perform hierarchical regression and construct the corresponding regression model, and the following results were obtained (as shown in TABLE IV).

In order to verify $\mathrm{H} 1$ and $\mathrm{H} 2$, firstly, entrepreneurs' creative thinking and optimism degree are the independent variables, the innovation opportunity identification as the dependent variable, and the Enter method is used to carry out the hierarchical regression and construct the corresponding regression model (corresponding to model 2 and model 4 in TABLE IV). Secondly, the natural and square terms of the above variables were taken as independent variables, and the innovation opportunity identification was taken as dependent variables. The Enter method was used for hierarchical regression and the corresponding regression model was constructed (corresponding to model 3 and model 5 in TABLE IV). Finally, according to the verification process of inverted ushaped relation, the significance of the model and corresponding coefficients after adding square terms of each variable is tested.

By comparing the statistical results of model 2 and model 3 in TABLE IV, it can be seen that when controlling for variables such as gender, age, founder identity, position, nature and size, entrepreneurs' nature of creative thinking has a significant positive influence on innovation opportunity identification effect $(\mathrm{P}<0.001)$. after joining squared creative thinking, not only the model is still significant, and creative thinking natural items and squared coefficient is also significant $(\mathrm{P}<0.001)$. Since the coefficient of creative thinking in model 2 is positive, the natural term coefficient of creative thinking in model 3 is positive and the square term coefficient is negative, there is an inverted u-shaped relationship between entrepreneurs' creative thinking and innovation opportunity identification, thus verifying H1.And so $\mathrm{H} 2$ is verified.

In order to verify $\mathrm{H} 3$, firstly, the entrepreneur's creative thinking and optimism degree are the independent variables, and the innovation opportunity is recognized as the dependent variable to regress, and the model 6 is obtained. Secondly, the entrepreneur's creative thinking, optimism degree and interaction item of creative thinking were taken as independent variables, and the innovation opportunity identification was taken as dependent variable for regression, and model 7 was obtained. Finally, according to the positive impact verification process, the significance of the model and the corresponding coefficient after adding the interaction item of creative thinking was tested.

Comparing the statistical results of model 6 and model 7 in TABLE IV, it can be seen that in the case of controlling gender age, founder identity, position, nature, scale and other variables, the natural items of entrepreneurs' creative thinking and optimism degree have significant positive effects on innovation opportunity identification $(\mathrm{P}<0.001)$. After adding the interactive term of creative thinking, not only the model remained significant, but also the coefficients of the above three variables were significant $(\mathrm{P}<0.001)$. Because the coefficient of entrepreneurial creative thinking and optimism degree in model 6 is positive, the entrepreneurs' creative thinking, optimism degree and creative thinking interaction coefficient in model 7 are positive, so entrepreneurs' optimism degree positively regulates the positive influence of creative thinking on innovation opportunity identification, and $\mathrm{H} 3$ is verified.

TABLE IV. TEST RESUlTS OF CREATIVE THINKING, OPTIMISM AND INNOVATION OPPORTUNITY IDENTIFICATION RELATIONSHIP MODEL

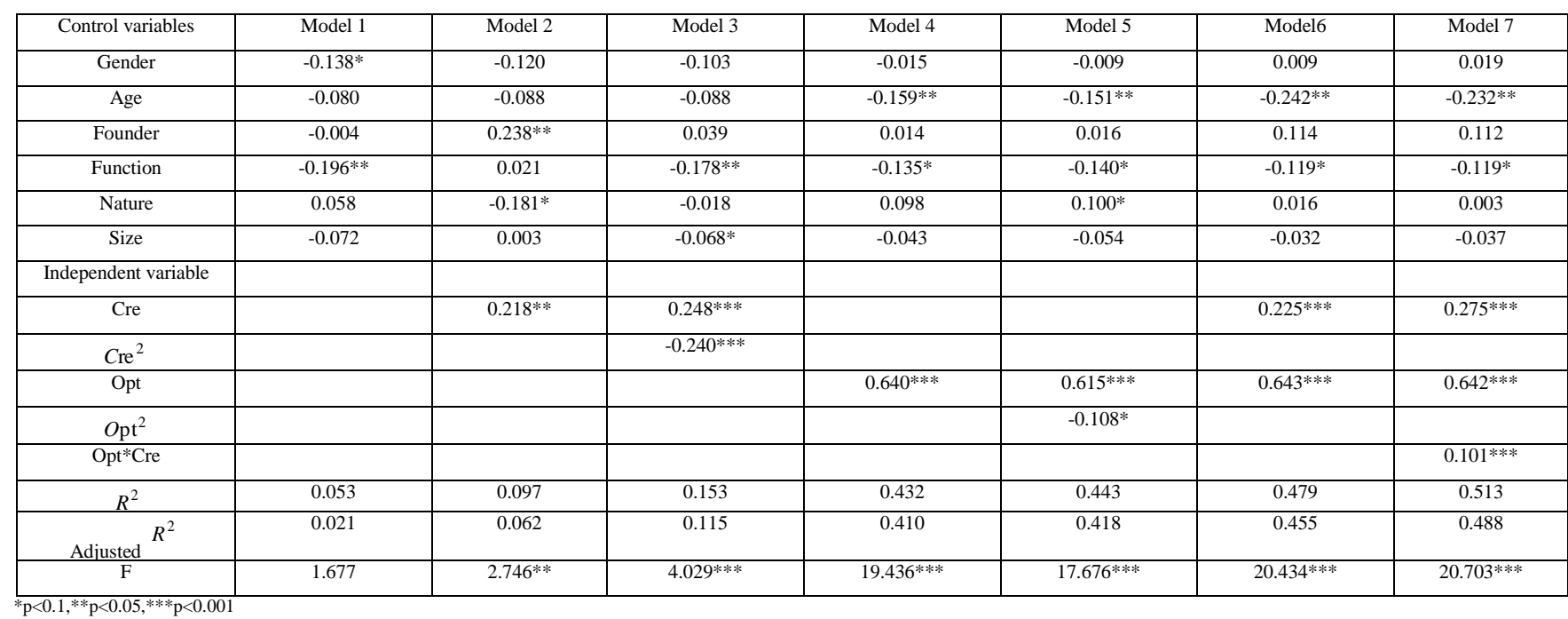




\section{CONCLUSION}

\section{A. Research Conclusions}

In order to clarify the complex relationship between entrepreneurs' creative thinking, optimism degree and innovation opportunity identification, this paper builds a relationship model between entrepreneurs' creative thinking, optimism degree and innovation opportunity identification based on relevant theories, and empirically tests the proposed hypothesis based on 187 valid sample data. The research hypothesis of this paper is basically supported, and the conclusions are as follows:

This study deeply analyzes the influence of entrepreneurs' creative thinking, optimism degree on the innovation opportunity identification and the adjustment of optimism degree. The results show that there is an inverted U-shaped relationship between entrepreneurs' creative thinking and innovation opportunity recognition, and there is an inverted U-shaped relationship between optimism degree and innovation opportunity recognition. Entrepreneurs' optimism degree positively regulates the influence of creative thinking on innovation opportunity recognition.

\section{B. Research Implications}

The conclusions of this study further deepen the theory of enterprise innovation, and have a strong practical guiding role for entrepreneurial innovation education.

1) In daily life and work, the cultivation of entrepreneurs' creative thinking should be strengthened, and constantly try to reorganize and identify different fields and different types of information, and strive to identify innovative opportunities and obtain innovative results through creative thinking activities. Improving the feasibility of entrepreneurial opportunities and the ability to identify profitable, and thus promote the success rate of entrepreneurship.

2) Entrepreneurs' moderate optimism will help them identify innovation opportunities. The study shows that there is a significant inverted U-shaped relationship between entrepreneurs' optimism degree and innovation opportunity identification, and optimism positively regulates the relationship between entrepreneurs' creative thinking and innovation opportunity identification. Therefore, entrepreneurs should pay attention to the management of their emotions and establish positive emotional perception.

\section{Insufficient and Prospects}

There are some limitations in this study. Firstly, the paper only uses 187 valid sample data as the basis for hypothesis verification. The universality of relevant conclusions needs to be further strengthened. This is the unfinished part of this paper. In the later stage, the generality of the conclusion can be expanded by industry and sub-region. Secondly, in order to focus on the entrepreneurs' creative thinking, optimism degree and innovation opportunity identification mechanism, the author presupposed the interaction relationship and the direction of interaction among the latent variables, so it was impossible to deeply explore the potential relationship between the variables. Later, other analysis techniques can be used to further explore the possible other action paths among the variables involved in this paper.

\section{ACKNOWLEDGMENT}

This work was supported by regional project of national natural science foundation of China(the project number is 71764033), supported by applied basic research project of Yunnan(the project number is 2017FB101), supported by the graduate innovation fund project of Yunnan University of Finance and Economics (the project number is 2020YUFEYC014). Thank for all the sponsors.

\section{REFERENCES}

[1] J.C. Short, D.J. Ketchen, and C.L. Shook, "The concept of " opportunity" in entrepreneurship research: past accomplishments and future challenges," Journal of Management, 2010, pp. 40-65.

[2] M.N. Zhang, and H.L. Li, "Framework analysis of entrepreneur opportunity recognition based on resource endowment," Management World, vol. 21, 2005, pp. 158-159.

[3] G. Huang, "Research on the relationship between college students" entrepreneurship alertness and entrepreneurial opportunity recognition_taking Hangzhou city as an example," 2014.

[4] A. Ardichvili, R. Cardozo, and S. Ray, "A theory of entrepreneuria opportunity identification and development," Journal of Business Venturing, vol. 18, 2003, pp. 105-123.

[5] A. Cocu, E. Pecheanu, and I. Susne, "Stimulating creativity through collaboration in an innovation laboratory," Social and Behavioral Sciences, vol. 182, 2015, pp. 173-178.

[6] X.E. Zhang, "Research on the relationship between entrepreneurial alertness, creative thinking and entrepreneurial opportunity identification," Social Science Front, 2013, pp. 78-84.

[7] K.S. Bulter , and J. Alertness, "Bisociative thinking ability, and discovery of entrepreneurial opportunities in Asian hitech firms, Babson: Babson College," Babson Kauffman Entrepreneurship Research Conference, 2013, pp. 78-106.

[8] X. Yao, Q. Yang, and N. Dong, "Moderating effect of zhong yong on the relationshiop between creativity and innovation behavior," Asia Journal of Social Psychology, 2010, pp. 53-57.

[9] F. Niu, Y.L. Zhang, and L. Tian, "Entrepreneur's self-confidence, optimism and new corporate performance - an empirical study based on 145 new companies," Economic Management, vol. 34, 2012, pp. 83-93.

[10] A.M. Goel, and A.V. Tnakor, "Overconfidence, CEO selection, and corporate governance," Journal of Finance, 2008, pp. 2737-2784.

[11] U. Malmendier, and G. Tate, "Who makes acquisitions? CEO overconfidence and the market's reaction," Journal of Financial Economics, vol. 21, 2008, pp. 20-43.

[12] Y.P. Xie, and G.L. Wang, "Familial resources, entrepreneurial action learning and family entrepreneurship - optimistic regulatory role," Research Management, vol. 37, 2016, pp. 98-106.

[13] J.P. Yang, P.P. Chen, and S.Z. Bao, "The influence of cognitive bias and self-efficacy on entrepreneurial risk Perception-A comparative analysis of novice and continuous entrepreneurs," Journal of Zhejiang Sci-Tech University, vol. 18, 2019, pp. 140-148.

[14] R.A. Baron, "The roal of affect in the entrepreneurial process," Academy of Management Revie, 2008, pp. 328-340.

[15] E. Ozgen, "Entrepreneurial opportunity recognition: information flow, social and cognitive perspectives," New York: Rensselaer Polytechnic Institute, vol. 30, 2003, pp. 20-43.

[16] B. Cui, Y.X Wang, "Supply network connection strength and risk sharing: dependence on asymmetric regulation," Management World, 2017, pp. 106-118 